\title{
Penerapan Metode K-Means Dan Apriori Untuk Pemilihan Produk Bundling
}

\author{
Syifa Aryanti ${ }^{1}$, Deni Mahdiana ${ }^{2}$, Ade Setiadi $^{3}$ \\ ${ }^{1,2}$ Program Studi Magister Ilmu Komputer Universitas Budi Luhur, \\ ${ }^{3}$ Program Studi Teknik Informatika Universitas Raharja \\ Email : ${ }^{* 1}$ 1811600194@ student.budiluhur.ac.id, ${ }^{2}$ deni.mahdiana@budiluhur.ac.id, \\ 3adesetiadi@raharja.info
}

\begin{abstract}
Abstrak
Sistem penunjang keputusan sangat berpengaruh terhadap strategi perusahaan dalam memutuskan sebuah program rekomendasi yang dapat mengatasi persaingan penjualan yang berubah mengikut tren setiap waktunya dan dampak wabah pandemi Covid-19 mengakibatkan penurunan penjualan dan daya tarik konsumen yang drastis dalam kurun waktu Januari - Maret 2020 hal ini merupakan sebuah peringatan dan ancaman bagi perusahaan bahwa persaingan penjualan semakin besar. PT. MSD merupakan distributor alat-alat dapur dan produk fashion middle-up dari berbagai brand terkenal seperti Jansport, Butterfly Twist, Thermos, Serena, Bodum, Arcoroc Luminarc dan sebagainya. Faktor persaingan penjualan dan dampak wabah pandemi Covid-19 yang dihadapi PT. MSD memicu perusahaan harus menyiapkan program penjualan baru dengan strategi product bundling sebagai promosi yang inovatif. Penerapan metode K-Means dan Apriori pada strategi product bundling ini diperoleh dari hasil Market Basket Analysis dan data penjualan PT. MSD untuk menghasilkan rekomendasi produk pilihan yang ter-klasterisasi dengan sistematis dan terukur agar PT. MSD dapat meningkatkan penjualan dan daya tarik konsumen dengan pilihan produk rekomendasi yang dibutuhkan konsumen.
\end{abstract}

Kata kunci: Sistem Informasi, K-Means dan Apriori, Produk Bundling.

\begin{abstract}
The decision support system is very influential on the company's strategy in deciding a recommendation program that can overcome sales competition that changes according to trends every time and the impact of the Covid-19 pandemic has resulted in a drastic decline in sales and consumer attractiveness in the period January - March 2020, this is a a warning and a threat to the company that sales competition is getting bigger. PT. MSD is a distributor of kitchen utensils and middle-up fashion products from various well-known brands such as Jansport, Butterfly Twist, Thermos, Serena, Bodum, Arcoroc Luminarc and so on. Sales competition factors and the impact of the Covid-19 pandemic outbreak faced by PT. MSD triggers the company to prepare a new sales program with a product bundling strategy as an innovative promotion. The application of the K-Means and Apriori methods to the product bundling strategy was obtained from the results of Market Basket Analysis and sales data of PT. MSD to produce selected product recommendations that are clustered systematically and measurably so that PT. MSD can increase sales and consumer attractiveness with a choice of recommended products that consumers need.
\end{abstract}

Keywords: Information Systems, K-Means and Apriori, Bundling Products. 


\section{PENDAHULUAN}

Perkembangan industri pendukung sektor bisnis hospitality (hotel, restaurant dan cafe) memiliki peranan strategis dalam meningkatkan pertumbuhan ekonomi Indonesia. PT. MSD sebagai salah satu distributor alat-alat dapur dan produk fashion multi brand ternama menargetkan penjualan di 2020 meningkat dari tahun sebelumnya. Hal ini perlu menjadi perhatian khusus bahwa penjualan PT. MSD pada awal tahun 2020 mengalami penurunan yang drastis dampak dari persaingan penjualan dan munculnya wabah pandemi Covid-19 pada Februari 2020 yang mengakibatkan pemerintah menerapkan aturan penutupan sementara pusat perbelanjaan dan pembatasan lain yang perlu dipatuhi oleh masyarakat Indonesia. Dampak dari wabah pandemi Covid-19 mengakibatkan PT. MSD mengalami penurunan penjualan sebanyak 27,41\% pada Januari - Maret 2020 di divisi penjualan Project, Hotel, Restaurant dan Café (Horeca) serta Traditional Market, Penurunan penjualan pun terjadi sebanyak 48,93\% pada Januari - Maret 2020 di divisi penjualan Retail Store yang target konsumen nya adalah konsumen di pusat perbelanjaan, Maka dengan penurunan penjualan yang tengah dialami PT. MSD, PT. MSD harus menerapkan berbagai strategi baru dalam mengembangkan promosi dan penjualannya salah satu nya adalah penerapan program penjualan baru dengan strategi product bundling, PT. MSD bergerak dalam industri distributor yang mendistribusikan ribuan item produk ke seluruh Indonesia ini seharusnya telah memiliki sistem yang baik untuk memilih produk rekomendasi pada strategi product bundling secara sistematis dan terukur. Sementara metode konvensional tidak bisa diterapkan pada strategi tahap lanjut maka metode pemilihan produk harus diperbaiki dengan metode K-Means dan Association Rule Mining yang menganalisa data penjualan PT. MSD periode 2019-2020 dengan memahami Market Basket Analysis konsumen sehingga dapat menentukan produk rekomendasi pada penerapan strategi product bundling.

\section{METODE PENELITIAN}

Metodologi pada Penelitian ini yakni menggunakan CRISP-DM untuk melakukan analisa dan mengolah data. Tahapan penelitian dibagi ke dalam beberapa tahap seperti dibawah ini :

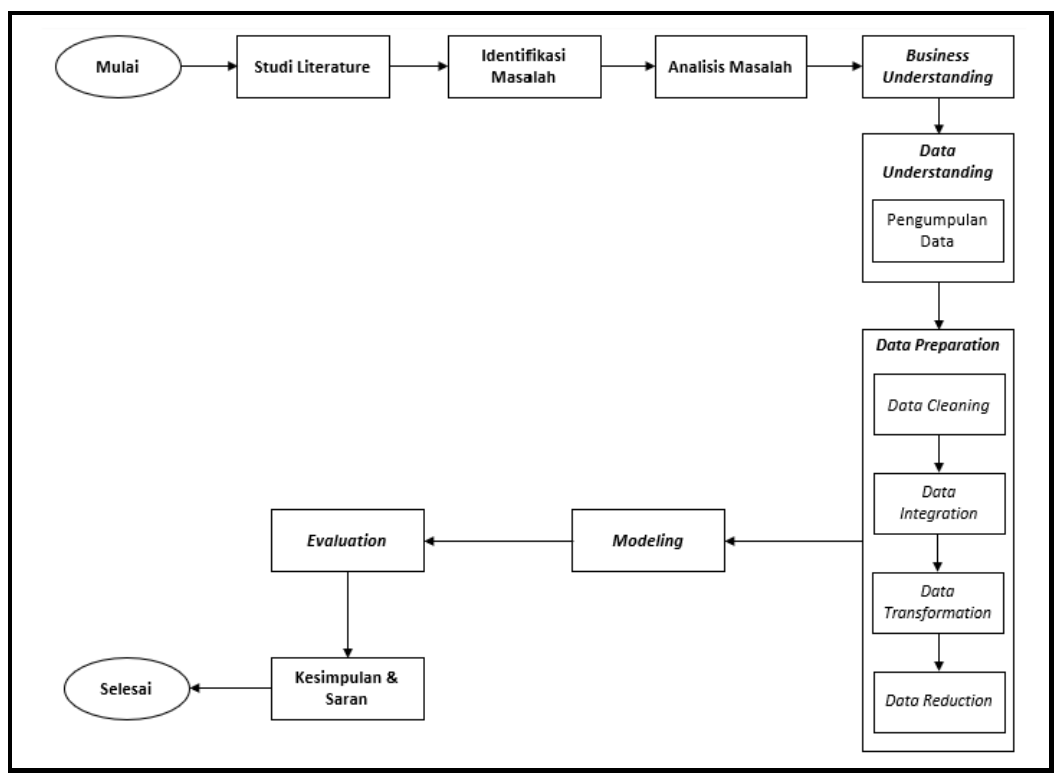

Gambar 1. Tahapan Penelitian 
A. Studi Literature

Pada tahap ini adalah tahap menggali informasi lebih lanjut tentang penerapan metode K-Means dan Apriori terhadap penelitian yang terkait. Penelitian ini memiliki Literature Review sebagai berikut :

1. Penelitian yang dilakukan oleh Bayu (2010) dengan judul : "Penetapan Strategi Penjualan Menggunakan Association Rules dalam Konteks Customer Relationship Management (CRM)" dengan tujuan menganalisa data transaksi dengan konsep data mining untuk menghasilkan sistem rekomendasi barang yang digunakan sebagai solusi alternatif seperti cross/up selling, product affinity analysis dan product bundling.

2. Penelitian selanjutnya dilakukan oleh Derdenger and Kumar (2013) dengan judul penelitian "The Dynamic Effects of Bundling as a Product Strategy" dengan tujuan menganalisa data transaksi untuk menentukan strategi Product Bundling dengan metode analisa kualitatif dan perilaku konsumen.

3. Penelitian selanjutnya dilakukan oleh Kuswayati dan Tjahyadi (2015) dengan judul penelitian "Market Basket Analysis Menggunakan Algoritma Apriori Untuk Penetapan Strategi Bundling Penjualan Barang" dengan tujuan menganalisa data transaksi untuk menentukan strategi Product Bundling dengan dua kondisi penjualan produk menumpuk dan kenaikan omset produk paling laris.

4. Penelitian selanjutnya dilakukan oleh Latifah, Furqon and Santoso (2018) dengan judul penelitian "Implementasi Algoritma Modified-Apriori Untuk Menentukan Pola Penjualan Sebagai Strategi Penempatan Barang Dan Promo" dengan tujuan menganalisa data transaksi untuk menentukan strategi penempatan barang dan promosi penjualan sehingga membentuk pola itemset.

5. Penelitian selanjutnya dilakukan oleh Wiji Setyaningsih (2014) dengan judul penelitian "Sistem Pendukung Keputusan Dalam Penentuan Bundling Penjualan Barang Dengan Metode Apriori" dengan tujuan menganalisa data transaksi untuk menentukan paket Product Bundling agar dapat mengoptimalkan laba yang diperoleh.

B. Identifikasi Masalah

Identifikasi Masalah pada tahap ini untuk menghitung pembentukan klasterisasi dan rekomendasi item dengan metode K-Means dan Association Rule Mining.

C. Analisis Masalah

Analisis Masalah disini yakni melakukan analisa permasalahan yang terkait dengan penelitian. Pada tahap ini di lakukan sub tahap di mana metodologi CRISP-DM diterapkan. Pada proses CRISP-DM dapat dijelaskan sebagai berikut:

1. Business Understanding

Yang berarti fokus terhadap pemahaman sasaran atau tujuan yang ingin dicapai pada penelitian ini serta strategi jadwal penelitian.

2. Data Understanding

Yang berarti fokus terhadap pemahaman data untuk bisa mengenal data seperti apa yang akan dipakai untuk keperluan penelitian. Pengumpulan data yang sekunder ini bersumber dari PT. MSD periode Januari - Maret 2020.

3. Data Preparation

4. $\quad$ Modeling

Pada penelitian ini menggunakan data cleaning dan transformation data.

Modeling yang dilakukan ini yakni proses peng-klasterisasi data yang terklasterisasi dan menghasilkan sejumlah aturan. Pada penelitian ini dipakai metode K-Means dan Association Rule Mining.

5. Evaluation

Evaluation untuk metode K-Means dan Association Rule Mining ini dapat menghasilkan klaster dan pola asosiasi produk rekomendasi pilihan yang potensial untuk diterapkan pada strategi product bundling. 
D. Analisis Sistem

Analisis Sistemnya seperti dibawah ini :

1. Melakukan pengembangan sistem server (admin) yang berupa sebuah form pengisian data yang berhubungan dengan sebuah transaksi penjualan.

2. Melakukan pengembangan sistem client (user) yang berupa form diisi client yang mengakses server service system dan melakukan counting klasterisasi serta perhitungan rekomendasi item.

\section{HASIL DAN PEMBAHASAN}

Dalam hasil dan pembahasan ini, sistem dibagi menjadi 2 (dua) bagian : 1) Proses dalam membuat klasterisasi menggunakan metode $K$-Means, mengimplementasikan dari aturan-aturan $K$-Means berdasarkan data-data yang diperoleh dari penelitian. 2) Proses visualisasi output $K$ Means yang dihitung kembali dengan metode Association Rule Mining. Langkah pertama yang mesti diperhatikan ialah mencari nilai output proses klasterisasi pada penggunaan metode $K$ Means. Terdapat 6 (enam) langkah yang harus dilaksanakan, antara lain :

\section{Pembentukan Himpunan Klasterisasi}

Pada tahap ini akan dijelaskan mengenai penerapan metode K-Means akan menghitung nilai davies bouldin index atribut terpilih agar membentuk 2 (dua) klaster yaitu klaster slow moving product dan klaster fast moving product dan menentukan centroid awal, centroid awal diperoleh secara acak dengan penerapan metode K-Means menggunakan RapidMiner seperti yang ditampilkan pada tabel 1.

Tabel 1. Centroid Awal

\begin{tabular}{|l|c|r|r|r|}
\hline \multirow{2}{*}{ Centroid } & \multirow{2}{*}{ Klaster } & \multicolumn{3}{|c|}{ Atribut } \\
\cline { 2 - 5 } & & \multicolumn{1}{|c|}{ No } & \multicolumn{1}{|c|}{ Qty } & \multicolumn{1}{c|}{ UnitPrice } \\
\hline \multirow{2}{*}{ Centroid 0 } & $\mathrm{C} 0$ & 17,00 & 9,00 & 153,00 \\
\cline { 2 - 5 } & $\mathrm{C} 1$ & 19,00 & 30,00 & 570,00 \\
\hline \multirow{2}{*}{ Centroid 1 } & $\mathrm{C} 0$ & 117,56 & 456,67 & 165,88 \\
\cline { 2 - 5 } & $\mathrm{C} 1$ & 807,52 & $7.570,20$ & $1.319,72$ \\
\hline \multirow{2}{*}{ Centroid 2 } & $\mathrm{C} 0$ & 140,17 & 387,72 & $1.118,58$ \\
\cline { 2 - 5 } Centroid 3 & $\mathrm{C} 1$ & $3.357,56$ & $35.640,00$ & 196,55 \\
\hline \multirow{2}{*}{ Centroid 4 } & $\mathrm{C} 0$ & 252,98 & $1.074,70$ & $1.060,43$ \\
\cline { 2 - 5 } & $\mathrm{C} 1$ & $4.645,40$ & $56.010,20$ & 121,78 \\
\cline { 2 - 5 } & $\mathrm{C} 0$ & 263,64 & $1.507,93$ & $1.044,95$ \\
\hline & $\mathrm{C} 1$ & $5.589,00$ & $63.462,25$ & 111,58 \\
\hline
\end{tabular}

sehingga diperoleh nilai persamaan Eucladian Distance Space yang dapat dilihat pada persamaan 1 .

$$
\sqrt{(x-\text { Centroid } 1) \wedge 2+(y-\text { Centroid } 2) \wedge 2+(z-\text { Cent }}
$$

\section{a. Iterasi 0}

Item $1(C 0)=\sqrt{(284-17) \wedge 2+(1.184-9) \wedge 2+(244-153) \wedge 2}=1.208$

Item $1(C 1)=\sqrt{(284-19) \wedge 2+(1.184-30) \wedge 2+(244-570) \wedge 2}=1.228$

\section{b. Iterasi 1}


Item $1(C 0)=\sqrt{(284-118) \wedge 2+(1.184-457) \wedge 2+(244-116) \wedge 2}=750$

Item $1(C 1)=\sqrt{(284-808) \wedge 2+(1.184-7.570) \wedge 2+(244-1.320) \wedge 2}=6.497$

\section{c. Iterasi 2}

Item $1(C 0)=\sqrt{(284-140) \wedge 2+(1.184-388) \wedge 2+(244-1.119) \wedge 2}=1.192$

Item $1(C 1)=\sqrt{(284-3.358) \wedge 2+(1.184-35.640) \wedge 2+(244-197) \wedge 2}=34.953$

\section{d. Iterasi 3}

Item $1(C 0)=\sqrt{(284-253) \wedge 2+(1.184-1.075) \wedge 2+(244-1.060) \wedge 2}=825$

Item $1(C 1)=\sqrt{(284-4.645) \wedge 2+(1.184-56.010) \wedge 2+(244-122) \wedge 2}=55.000$

\section{e. Iterasi 4}

Item $1(C 0)=\sqrt{(284-264) \wedge 2+(1.184-1.508) \wedge 2+(244-1.045) \wedge 2}=864$

Item $1(C 1)=\sqrt{(284-5.589) \wedge 2+(1.184-63.642) \wedge 2+(244-112) \wedge 2}=62.504$

Pada persamaan 2.1 untuk Item 1 dengan variabel No (x), variabel Qty (y) dan variabel UnitPrice (z) dari percobaan perhitungan (perulangan) iterasi 0-4 jarak ke pusat klaster menghasilkan perhitungan konsisten yaitu hasil $\mathrm{C} 0<=\mathrm{C} 1$ (tidak berpindah) maka Item 1 termasuk ke dalam klaster $\mathrm{C} 0$ yaitu klaster slow moving product kemudian hasil Implementasi metode K-Means menggunakan RapidMiner menghasilkan nilai Davies Bouldin-Index dengan tingkat keakuratan yang optimal karena semakin mendekati 0 (nol) seperti yang ditampilkan pada gambar 2.

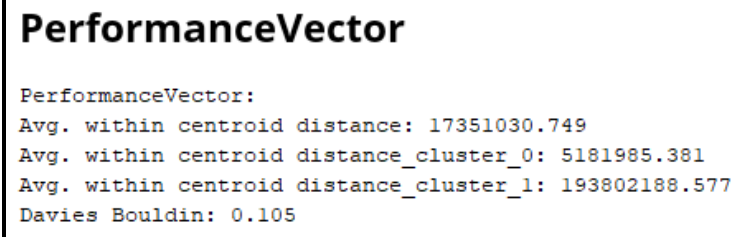

\section{Gambar 2. Hasil Nilai Davies Bouldin-Index RapidMiner}

\section{Pengujian Pembentukan Himpunan Klasterisasi Menggunakan SPSS}

Proses pengujian metode K-Means menggunakan SPSS menghasilkan deskripsi variabel yang paling berpengaruh tinggi dalam pembentukan klaster yaitu variabel Qty dengan standar deviasi sebesar 17424,48186 dan tingkat pengaruh dalam pembentukan klaster sedang yaitu variabel No dengan standar deviasi 1579,90781 sedangkan tingkat pengaruh dalam pembentukan klaster terendah yaitu variabel Unit Price dengan standar deviasi sebesar 1296,90491 seperti yang ditampilkan pada tabel 2.

Tabel 2. Hasil Deskripsi Variabel Descriptive Statistics

\begin{tabular}{|c|c|c|c|c|c|}
\hline & N & Minimum & Maximum & Mean & Std. Deviation \\
\hline No & 62 & 1,00 & 7717,00 & 607,2097 & 1579,90781 \\
Qty & 62 & 1,00 & 110269,00 & 5504,9839 & 17424,48186 \\
UnitPrice & 62 & 21,00 & 5984,00 & 984,7419 & 1296,90491 \\
Valid N (listwise) & 62 & & & & \\
\hline
\end{tabular}

Tingkat pengaruh ini dibuktikan dengan nilai signifikasi variabel No (x) adalah 0,000 $<0,005$, maka model regresi dapat dipakai untuk memprediksi variabel Qty (y) atau 
dengan kata lain terdapatnya pengaruh variabel No (x) terhadap variabel Qty (y) seperti yang ditampilkan pada tabel 3 .

Tabel 3. Hasil Nilai Signifikasi Variabel ANOVA $^{\mathrm{a}}$

\begin{tabular}{|c|c|c|c|c|c|c|}
\hline \multicolumn{1}{|c|}{ Model } & Sum of Squares & df & Mean Square & F & Sig. \\
\hline 1 & Regression & 108587854,798 & 1 & 108587854,798 & 149,177 &, $000^{6}$ \\
& Residual & 43674775,476 & 60 & 727912,925 & & \\
& Total & 152262630,274 & 61 & & & \\
\hline
\end{tabular}

a. Dependent Variable: No

b. Predictors: (Constant), Qty

Hasil nilai Coefficients variabel No (x) terhadap variabel Qty (y) diketahui memiliki nilai Constant (a) sebesar 185,686, sedangkan nilai variabel No (b / koefisien regresi) sebesar 0,077 sehingga persamaan regresi nya dapat dilihat pada persamaan 2 .

$$
\begin{aligned}
& \mathrm{Y}=\mathrm{a}+\mathrm{bX} \\
& \mathrm{Y}=185,686+0,077
\end{aligned}
$$

Persamaan tersebut dapat diterjemahkan sebagai berikut:

1. Konstanta sebesar 185,686, mengandung arti bahwa konsisten variabel No (x) adalah sebesar 185,686.

2. Koefisien regresi $\mathrm{x}$ sebesar 0,077 menyatakan bahwa setiap penambahan $1 \%$ nilai variabel Qty (y), maka nilai variabel No (x) bertambah sebesar 0,077.

3. Koefisien regresi tersebut bernilai positif, sehingga dapat disimpulkan bahwa arah pengaruh variabel No (x) terhadap variabel Qty (y) adalah positif.

Tabel Coefficient antar variabel No (x) terhadap variabel Qty (y) dapat dilihat pada tabel 4.

Tabel 4. Hasil Nilai Coefficients Variabel X dan Y

Coefficients $^{\mathrm{a}}$

\begin{tabular}{|cc|c|c|c|c|c|}
\hline \multirow{2}{*}{ Model } & \multicolumn{2}{|c|}{ Unstandardized Coefficients } & Standardized Coefficients & & \\
\cline { 2 - 5 } & B & Std. Error & Beta & t & Sig. \\
\hline 1 & (Constant) & 185,686 & 113,717 & & 1,633 &, 108 \\
& Qty &, 077 &, 006 &, 844 & 12,214 &, 000 \\
\hline
\end{tabular}

a. Dependent Variable: No

Kemudian proses pengujian metode K-Means menggunakan SPSS menghasilkan klaster yang mendekati sama dengan hasil klaster menggunakan RapidMiner yaitu jumlah item pada klaster slow moving product (C) sebanyak 57 item dan klaster fast moving product $(\mathrm{C} 1)$ sebanyak 5 item dari total 62 item maka tingkat keakuratan pengujian adalah tinggi.

\section{Pengujian Pembentukan Himpunan Klasterisasi Menggunakan Metode Association Rule Mining}

Proses pengujian menggunakan tools RapidMiner Studio Educational versi 9.5. terdiri dari beberapa tahap, yaitu:

1. Menentukan minimum support dan minimum confidence, minimum support diperoleh dari penelitian sebelumnya yang didefinisikan oleh penulis lain "Nilai minimum support ditetapkan sebesar $10 \%$ dan nilai minimum confidence ditetapkan sebesar 70\%" (Lusa, 2019). 
2. Menghitung item-item untuk iterasi ke-1 dari support (transaksi yang memuat seluruh item) dengan memindai database untuk 1-itemset kemudian 1-itemset dihitung apakah jumlah minimum support sudah terpenuhi seperti 10 sampel item yang ditampilkan pada tabel 5 .

Tabel 5. Iterasi ke-1

\begin{tabular}{|l|c|c|}
\hline \multicolumn{3}{|c|}{ Iterasi 1 } \\
\hline \multicolumn{1}{|c|}{ Item } & Support Count & \% Support \\
\hline Chopper & 774 & $4,78 \%$ \\
\hline Coffee Capsule & 1211 & $27,82 \%$ \\
\hline Coffee Maker & 285 & $43,53 \%$ \\
\hline Cup dan Mug (Drink Set) & 362 & $10,24 \%$ \\
\hline Fork & 625 & $13,01 \%$ \\
\hline Knife & 310 & $22,47 \%$ \\
\hline Spoon & 802 & $9,13 \%$ \\
\hline
\end{tabular}

3. Menghitung item-item untuk iterasi ke-2 dari support (transaksi yang memuat seluruh item) dengan memindai database untuk 2-itemset yang terbentuk kemudian 2-itemset tersebut dipilih berdasarkan jumlah minimum support yang terpenuhi seperti yang ditampilkan pada tabel 6 .

Tabel 6. Iterasi ke-2

\begin{tabular}{|c|c|c|c|c|}
\hline \multicolumn{5}{|c|}{ Iterasi 2 } \\
\hline Item & Support Count & \% Support & \% Confidence & Lift \\
\hline Chopper, Fork & 363 & $13,05 \%$ & $46,90 \%$ & 2,09 \\
\hline Chopper, Spoon & 413 & $14,85 \%$ & $53,36 \%$ & 1,85 \\
\hline Fork, Spoon & 586 & $21,06 \%$ & $93,76 \%$ & 2,63 \\
\hline
\end{tabular}

4. Tetapkan nilai K-itemset dari support yang telah memenuhi minimum support $10 \%$ dari $>=2$-itemset kemudian lakukan proses untuk iterasi selanjutnya hingga tidak ada lagi $>=2$-itemset yang memenuhi minimum support $10 \%$ seperti yang ditampilkan pada tabel 7 .

Tabel 7. Iterasi ke-3

\begin{tabular}{|c|c|c|c|c|}
\hline \multicolumn{5}{|c|}{ Iterasi 3 } \\
\hline Item & $\begin{array}{c}\text { Support } \\
\text { Count }\end{array}$ & \% Support & \% Confidence & Lift \\
\hline $\begin{array}{c}\text { (Chopper, Fork), } \\
\text { Spoon }\end{array}$ & 355 & $12,76 \%$ & $97,80 \%$ & 1,59 \\
\hline
\end{tabular}

5. Tidak ada lagi kombinasi yang bisa dibentuk untuk K-itemset berikutnya, proses berhenti, pola frequent tinggi yang ditemukan adalah "Chopper, Fork, Spoon". Langkah berikutnya, bentuk association rules yang memenuhi syarat minimum support $10 \%$ dan menghitung minimum confidence association rules $\mathrm{A}->\mathrm{B} 70 \%$.

\section{Pengujian Metode Association Rule Mining Menggunakan Lift Ratio}

Proses pengujian metode Association Rule Mining pada hasil pola (rules) manual menggunakan Lift Ratio menghasilkan nilai lift ratio $>1$. Hal ini menunjukan bahwa semua pola (rule) tersebut bersifat kuat seperti yang ditampilkan pada persamaan 3 . 


$$
\begin{aligned}
& \text { Lift Ratio Chopper, Fork, Spoon }=\frac{97,80 \%}{0,29}=1,59 \\
& \text { Lift Ratio Fork, Spoon } \quad=\frac{93,76 \%}{0,29}=2,632
\end{aligned}
$$

Untuk mendapatkan nilai benchmark confidence sendiri dapat dihitung seperti yang ditampilkan pada persamaan 4 .

$$
\text { Benchmark Conf. Chopper, Fork, Spoon }=\frac{802}{2.782}=0,29
$$

$$
\text { Benchmark Conf.Fork, Spoon } \quad=\frac{802}{2.782}=0,29
$$

Hasil persamaan Support, Confidence dan lift ratio yang dibulatkan secara keseluruhan dapat dilihat pada tabel 8 .

Tabel 8. Pengujian Metode Association Rule Mining Menggunakan Lift Ratio

\begin{tabular}{|c|c|c|c|c|}
\hline Pengujian & Pola (Rules) & \% Support & \% Confidence & Lift \\
\hline \multirow{2}{*}{ RapidMiner } & Jika membeli Chopper dan Fork Maka membeli & $13 \%$ & $98 \%$ & 1,59 \\
\cline { 2 - 5 } & Jika membeli Fork maka membeli Spoon & $21 \%$ & $94 \%$ & 2,63 \\
\hline Aplikasi & Jika membeli Fork maka membeli Spoon & $21 \%$ & $94 \%$ & 2,63 \\
\hline
\end{tabular}

Hasil dari pembentukan aturan apriori menunjukan keterkaitan antar produk yang sering dibeli secara bersamaan sehingga membentuk market basket analysis. Berdasarkan nilai confidence tertinggi dan nilai lift ratio yang lebih dari 1 (satu) pada kombinasi itemset dapat menggambarkan keterkaitannya produk yang sering di beli oleh konsumen secara bersamaan sangat kuat.

\section{Implementasi Sistem Metode Association Rule Mining}

\section{A. Halaman Menu Login}

Halaman Menu Login ini adalah halaman untuk dapat masuk ke sistem dengan menginput username dan password seperti yang ditampilkan pada gambar 3 .

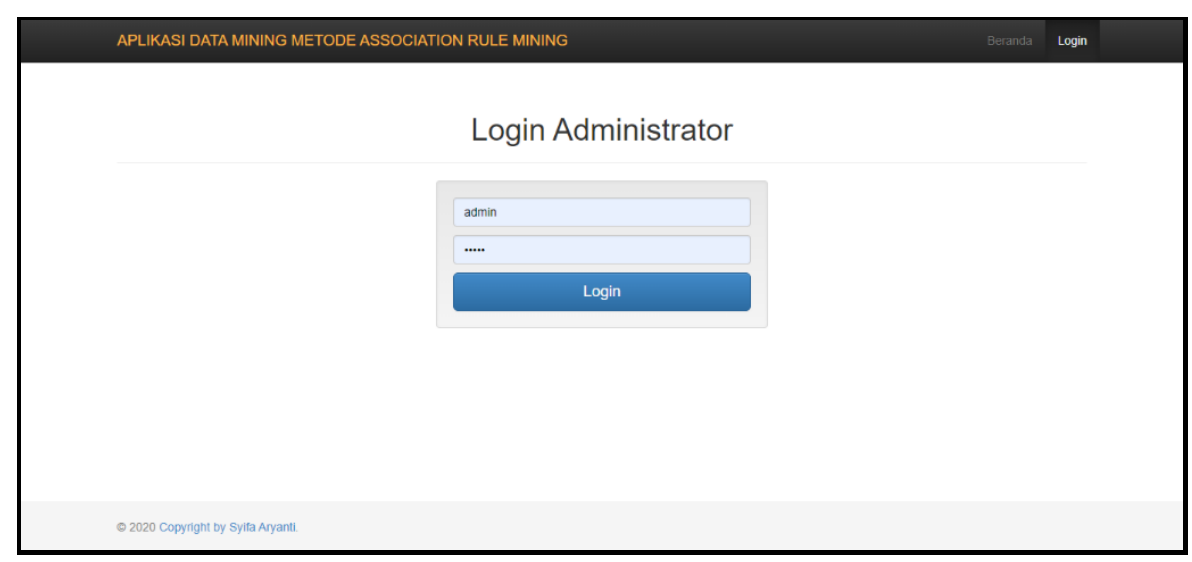

Gambar 3. Halaman Menu Login 


\section{B. Halaman Menu Beranda}

Halaman Menu Beranda ini adalah halaman utama pada sistem yang dapat masuk ke halaman lain seperti data barang, data transaksi, analisa, ubah password dan logout seperti yang ditampilkan pada gambar 4.

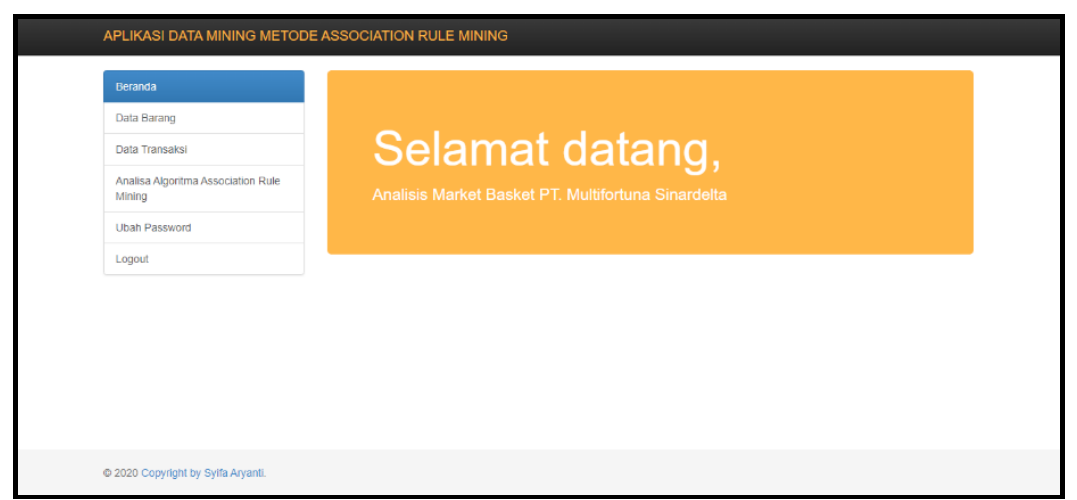

Gambar 4. Halaman Menu Beranda

\section{Halaman Menu Data Transaksi}

Halaman Menu Data Transaksi ini adalah halaman yang menampilkan daftar transaki dan fitur CRUD untuk menginput data transaksi dengan atribut kode transaksi dan barang yang terjual seperti yang ditampilkan pada gambar 5 .

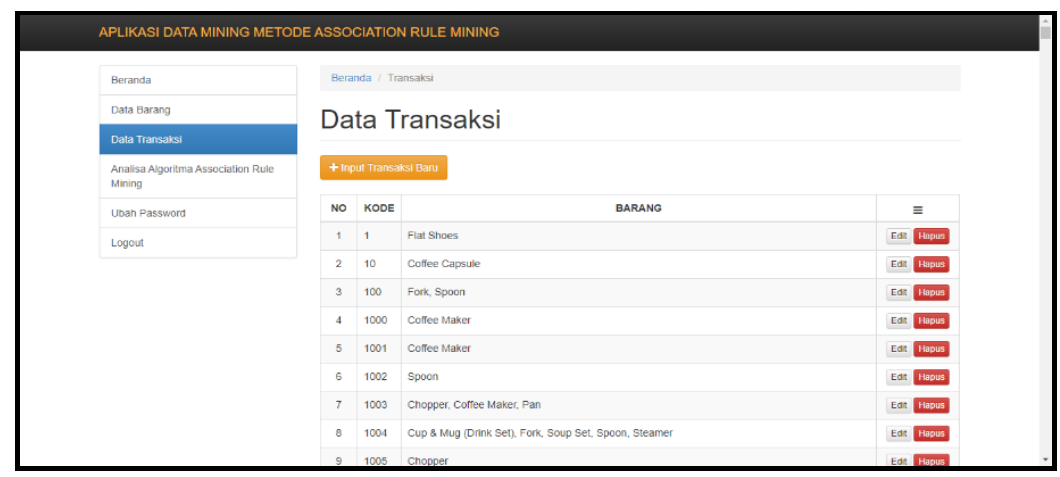

Gambar 5. Halaman Menu Data Transaksi

\section{Halaman Menu Analisa}

Halaman Menu Analisa ini adalah halaman yang menampilkan menu untuk menginput jumlah persentase minimum support dan confidence serta jumlah transaksi agar dapat di proses dengan algoritma apriori dan menghasilkan hasil analisa apriori seperti yang ditampilkan pada gambar 6 .

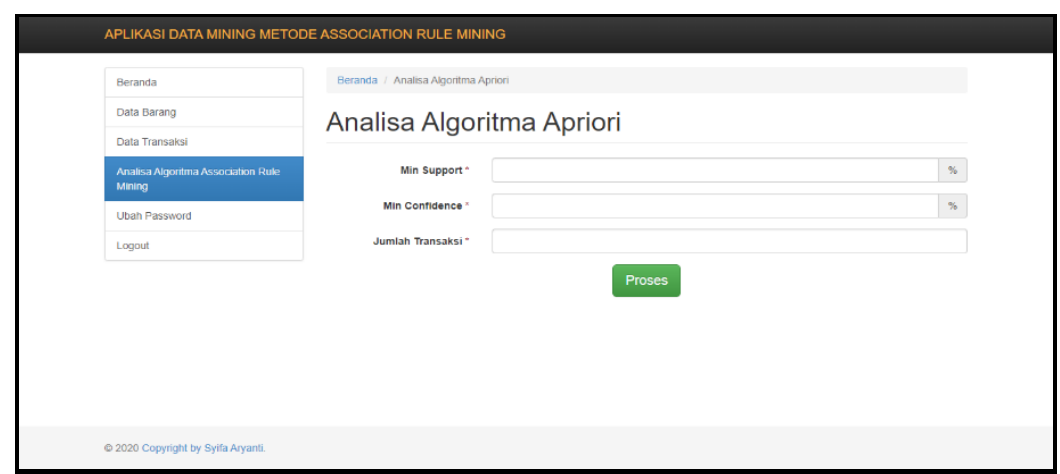

Gambar 6. Halaman Menu Analisa 


\section{Pengujian Kualitas Prototipe Data Mining}

Pengujian kualitas prototipe data mining dilakukan dengan membagikan kuesioner kepada 3 kelompok pengguna, yaitu Operational Manager, Head of e-Commerce dan staf admin. Pengujian hanya dilakukan untuk kelompok user pada level staff. Oleh karena itu, penelitian ini bertujuan untuk melakukan analisis terhadap prototipe data mining sehingga mendapatkan hasil tentang kondisi penjaminan kualitas perangkat lunak sesuai dengan kebutuhan user dan diterima oleh pengguna. Adapun hasil dari pengujian kualitas prototipe data mining ditampilkan pada tabel 9 dan 10 .

Tabel 9. Persentase Nilai

\begin{tabular}{|c|c|}
\hline \% Jumlah Skor & Kriteria \\
\hline $0,00-36 \%$ & Tidak Baik \\
\hline $36,1-52 \%$ & Kurang Baik \\
\hline $52,1-68 \%$ & Cukup \\
\hline $68,1-84 \%$ & Baik \\
\hline $84,1-100 \%$ & Sangat Baik \\
\hline
\end{tabular}

1. Correctness $=\mathrm{w} 1 \mathrm{c} 1+\mathrm{w} 2 \mathrm{c} 2+\mathrm{w} 3 \mathrm{c} 3$

$\begin{aligned} & =1,41+1,47+1,41=4,29 \\ \text { Persentase } & =4,29 * 20 / 100 \%=85,80 \% \text { (Sangat Baik) }\end{aligned}$

2. Reliability $=\mathrm{w} 1 \mathrm{c} 1+\mathrm{w} 2 \mathrm{c} 2+\mathrm{w} 3 \mathrm{c} 3$

$$
=1,41+1,32+1,72=4,45
$$

Persentase $\quad=4,45 * 20 / 100 \%=89,00 \%$ (Sangat Baik)

3. Efficiency $=\mathrm{w} 1 \mathrm{c} 1+\mathrm{w} 2 \mathrm{c} 2+\mathrm{w} 3 \mathrm{c} 3$

$\begin{aligned} & =1,35+1,29+1,35=3,99 \\ \text { Persentase } & =3,99 * 20 / 100 \%=79,80 \% \text { (Baik) }\end{aligned}$

4. Usability $=\mathrm{w} 1 \mathrm{c} 1+\mathrm{w} 2 \mathrm{c} 2$

$$
\begin{aligned}
& =1,76+1,76=3,52 \\
\text { Persentase } & =3,52 * 20 / 100 \%=70,40 \% \text { (Baik) }
\end{aligned}
$$

5. Maintainability $=\mathrm{w} 1 \mathrm{c} 1$

$$
\begin{aligned}
& =5,00=5,00 \\
\text { Persentase } & =5,00 * 20 / 100 \%=100,00 \%(\text { Sangat Baik })
\end{aligned}
$$

Perhitungan summary nilai:

$$
\begin{aligned}
\Sigma \quad & =\mathrm{wf} 1 * \mathrm{Fa} 1 * 2+\mathrm{wf} 2 * \mathrm{Fa} 2 * 2+\ldots+\mathrm{wfn} * \mathrm{Fan} * 2 \\
& =(3 * 4,29 * 2)+(2 * 4,45 * 2)+(2 * 3,99 * 2)+(2 * 3,52 * 2)+(1 * 5,00 * 2) \\
& =25,74+17,80+15,96+14,08+10,00 \\
& =83,58 * 100 \%=83,58 \% \text { (Baik) }
\end{aligned}
$$

Tabel 10. Persentase Nilai Akhir

\begin{tabular}{|c|c|}
\hline Faktor & Persentase \\
\hline Ketepatan (Correctness) & $\mathbf{8 5 , 8 0}$ (Sangat Baik) \\
\hline Kemudahan (Reliability) & $\mathbf{8 9 , 0 0}$ (Sangat Baik) \\
\hline Efisiensi (Efficiency) & $\mathbf{7 9 , 8 0}$ (Baik) \\
\hline Kegunaan (Usability) & $\mathbf{7 0 , 4 0}$ (Baik) \\
\hline Pemeliharaan & $\mathbf{1 0 0 , 0 0}$ (Sangat Baik) \\
\hline
\end{tabular}




\begin{tabular}{|c|c|}
\hline (Maintainability) & \\
\hline Total Nilai Seluruh Faktor & $\mathbf{8 3 , 5 8}$ (Baik) \\
\hline
\end{tabular}

Pada faktor correctness didapatkan nilai $85,80 \%$ yang menyatakan bahwa sistem menghasilkan nilai ketepatan yang diterima sesuai kebutuhan dengan sangat baik, kemudian pada faktor reliability didapatkan nilai $89,00 \%$ yang menyatakan bahwa sistem menyediakan kemudahan yang diterima sesuai kebutuhan dengan sangat baik, kemudian pada faktor efficiency didapatkan nilai $79,80 \%$ yang menyatakan bahwa efisiensi sistem diterima sesuai kebutuhan dengan baik.

kemudian pada faktor usability didapatkan nilai $70,40 \%$ yang menyatakan bahwa kegunaan sistem diterima sesuai kebutuhan dengan baik, dan pada faktor maintainability didapatkan nilai $100 \%$ yang menyatakan bahwa pemeliharaan sistem diterima sesuai kebutuhan dengan sangat baik. Dari total hasil pengujian kualitas prototipe didapatkan nilai $83,58 \%$ yang menyatakan bahwa sistem yang diterima sesuai kebutuhan oleh user dengan baik.

\section{KESIMPULAN}

Berdasarkan hasil penelitian Penerapan Metode K-Means dan Apriori Untuk Pemilihan Produk Bundling, dapat diambil kesimpulan sebagai berikut:

1. Penerapan Metode K-Means terbukti dapat menghasilkan klaster yang konsisten berhenti pada iterasi ke 4 dengan hasil klaster yang terbentuk sebanyak 58 item klaster slow moving product $(\mathrm{C} 0)$ dan sebanyak 4 item klaster fast moving product $(\mathrm{C} 1)$ dari total 62 item nilai Davies Bouldin-Index sebesar 0.106 dengan tingkat keakuratan yang optimal serta hasil uji validitas pembentukan klaster paling berpengaruh terdapat pada variabel No (x) dan variabel Qty (y) dengan nilai signifikansi variabel No (x) adalah 0,000, nilai Coefficients variabel No (x) sebanyak 185,686 dan nilai Koefisien regresi x sebesar 0,077 kemudian hasil pembentukan asosiasi produk rekomendasi menggunakan tools RapidMiner terhadap klaster item fast moving product $(\mathrm{C} 1)$ terbukti menghasilkan aturan asosiasi dari kombinasi itemset Chopper, Fork dan Spoon sebagai frequent itemset tertinggi dengan nilai support sebesar $12,76 \%$, nilai confidence sebesar $97,80 \%$ dan nilai lift ratio yang diperoleh sebesar 1,59 yang artinya aturan asosiasi tersebut bernilai valid dan benar dibeli secara bersamaan sehingga PT. MSD dapat mengatur strategi product bundling terhadap itemset yang memperoleh nilai support dan confidence tinggi.

2. Model Penerapan Metode K-Means dan Apriori Untuk Pemilihan Produk Bundling menggunakan metode black box dan white box testing dengan teknik Equivalence Partitioning pada semua data, uji sistem menunjukkan hasil sesuai kebutuhan dan status valid.

3. Model Penerapan Metode K-Means dan Apriori Untuk Pemilihan Produk Bundling menggunakan hasil pengujian dengan pendekatan metode McCall menyatakan bahwa sistem dapat memenuhi kebutuhan user dengan nilai sebesar 83,58\% (baik).

\section{SARAN}

Dari kesimpulan yang telah disebutkan diatas, penulis memberikan saran untuk pengembangan lebih lanjut dari Penerapan Metode K-Means dan Apriori Untuk Pemilihan Produk Bundling yaitu dengan pengembangan sistem terhadap bahasa yang lebih mudah dimengerti sehingga membantu user dalam menerima informasi yang dihasilkan serta penelitian 
ini dapat dikembangkan dengan penggabungan metode lain seperti Klasifikasi, FP-Growth dan masih banyak metode lainnya.

\section{DAFTAR PUSTAKA}

[1] Bayu Adhi Tama*, Fakultas Ilmu Komputer, U. S. A, 2010, Penetapan Strategi Penjualan Menggunakan Association Rules dalam Konteks CRM, Jurnal Generic, 5(1), pp. 35-38.

[2] Derdenger, T. and Kumar, V. (2013) The dynamic effects of bundling as a product strategy, Marketing Science, 32(6), pp. 827-859. doi: 10.1287/mksc.2013.0810.

[3] Wiji Setyaningsih, M. M. huda, 2014, Sistem Pendukung Keputusan dalam Penentuan Bundling Penjualan Barang dengan Metode Apriori, Bimasakti.

[4] Kuswayati, S. and Tjahyadi, D, 2015, Market Basket Analysis Menggunakan Algoritma Apriori Untuk Penetapan Strategi Bundling Penjualan Barang, pp. 1-18.

[5] Hidayati, A. et al, 2017, Analisa Kualitas Perangkat Lunak Sistem Informasi Akademik Menggunakan McCall, Multinetics, 3(1), p. 48. doi: 10.32722/vol3.no1.2017.pp48-53.

[6] Fitrina, N., Kustanto, K. and Wulandari, R. T, 2018, Penerapan Algoritma Apriori Pada Sistem Rekomendasi Barang Di Minimarket Batox, Jurnal Teknologi Informasi dan Komunikasi (TIKomSiN), 6(2), pp. 21-27. doi: 10.30646/tikomsin.v6i2.376.

[7] Kurniawan, E, 2018, Implementasi Data Mining Dalam Analisa Pola Peminjaman Buku Di Perpustakaan Menggunakan Metode Association Rule, Jurteksi, 5(1), pp. 89-96. doi: 10.33330/JURTEKSI.V5I1.324.

[8] Latifah, V. N., Furqon, M. T. and Santoso, N, ,2018, Implementasi Algoritme ModifiedApriori Untuk Menentukan Pola Penjualan Sebagai Strategi Penempatan Barang Dan Promo, Jurnal Pengembangan Teknologi Informasi dan Ilmu Komputer (J-PTIIK) Universitas Brawijaya, 2(10), pp. 2829-2834.

[9] Yuliani, E., Informatika, M. T. and Yogyakarta, U. A, 2019, Bundling Produk Dengan Metode Saw Dan Decision Support System for Product Bundling Promo With Saw and Apriori, pp. 131-139.

[10] Fauziyyah, A. and Mada, U. G, 2019, Algoritma apriori dalam menentukan product bundling, (July). 